\title{
Fiber Optic Sensing System for Monitoring of Coal Waste Piles in Combustion
}

D. Viveiros*a ${ }^{*}$ J. Ribeiro ${ }^{\text {b,c }}$, J.P. Carvalho ${ }^{\text {a }}$, J. Ferreira ${ }^{a}$, A.M.R. Pinto ${ }^{d}$, R. A. Perez-Herrera ${ }^{d}$, S. Diaz d, A. Lopez-Gile, A. Dominguez-Lopez ${ }^{\mathrm{e}}$, O. Esteban ${ }^{\mathrm{e}}$, H. F. Martins ${ }^{\mathrm{e}}$, S. Martin-Lopez ${ }^{\mathrm{e}}$, H. Baierlf ${ }^{\mathrm{f}}$, J.-L. Auguste ${ }^{\mathrm{f}}$, R. Jamier ${ }^{\mathrm{f}}$, S. Rougier ${ }^{\mathrm{f}}$, J. L. Santos ${ }^{\mathrm{a}, \mathrm{b}}$, D. Flores ${ }^{\mathrm{b}, \mathrm{c}}$, P. Roy ${ }^{\mathrm{f}}$, M. Gonzalez-Herraez ${ }^{\mathrm{e}}$,

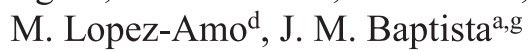

aINESC Porto - Unidade de Optoelectrónica e Sistemas Electrónicos, Rua do Campo Alegre, 687, 4169-007 Porto, Portugal; ' Faculdade de Ciências da Universidade do Porto, Rua do Campo Alegre, 687, 4169-007 Porto, Portugal; ' Centro de Geologia da Universidade do Porto e Dept. Geociências, Ambiente e Ordenamento do Território, Faculdade de Ciências da Universidade do Porto, Rua do Campo Alegre, 687, 4169-007 Porto, Portugal; dDept. Ingeniería Eléctrica y Electrónica, Universidad Pública de Navarra, Campus de Arrosadía, 31006 Pamplona - Navarra, Spain; ${ }^{\mathrm{e} D e p t . ~ d e ~}$ Electrónica, Universidad de Alcalá, Campus Universitario s/n, Alcalá de Henares 28871, España, ${ }^{\mathrm{f} C N R S}$, XLIM-Département Photonique-Fibre, Faculté des Sciences et Techniques 123, Avenue Albert Thomas, 87060 Limoges, France; ${ }^{g}$ Centro de Competência de Ciências Exatas e da Engenharia, Universidade da Madeira, Funchal, Portugal.

\begin{abstract}
The combustion of coal wastes resulting from mining is of particular environmental concern and therefore the importance of the proper management involving real-time assessment of their status and identification of probable evolution scenarios is recognized. Continuous monitoring of combustion temperature and emission levels of certain gases opens the possibility to plan corrective actions to minimize their negative impact in the surroundings. Optical fiber technology is well-suited to this purpose and in this work it is described the main attributes of a fiber optic sensing system projected to gather data on distributed temperature and gas emission in these harsh environments.
\end{abstract}

Keywords: Coal waste piles, combustion, fiber optic sensing, temperature sensing, gas sensing, environment.

\section{INTRODUCTION}

Spontaneous and self-combustion may occur during coal mining in storage piles, waste piles resulting from mining, and during transport. The environmental impact caused by the coal waste is associated with water and soil contamination, and becomes particularly serious when these waste piles are in self-combustion. The coal combustion is responsible for the mobilization of large quantities of pollutants caused by the volatilization of elements present in coal and the associated mineral matter ${ }^{1,2}$. The uncontrolled release of these pollutants, namely greenhouse gases, particulate matter, toxic elements, and especially organic compounds, represents a risk to the environment and to human health. These problems are even more serious when the coal waste piles are located near urban centers, since some of the pollutants can be inhaled or ingested. In this context, the monitoring of combustion temperature and gaseous emissions is essential to identify the associated hazards and probable evolution scenarios, allowing the definition of timely corrective measures to minimize the negative impacts caused by this phenomenon.

Aiming the remote, multi-point and continuous measurement of gas emissions (specifically ammonia, carbon dioxide and methane) and of combustion temperatures in self-burning coal waste piles, using optical fiber sensing technology, a R\&D INTERREG-SUDOE project entitled ECOAL - Ecological Management of Coal Waste Piles in Combustion is under development, with participation of groups from Portugal, Spain and France.

*carlos.d.viveiros@inescporto.pt; phone +351 22040 2301; inescporto.pt 
After laboratory development of the fiber based optoelectronic system for distributed temperature and gas emission measurement, in the spring of 2014 a prototype will be installed in a coal waste pile in self-combustion, located in S. Pedro da Cova, (Porto, Portugal), to evaluate its performance under field conditions. It is expected that the acquired knowledge and experience will allow the system optimization, opening up the possibility of its widespread application in other coal structures of this type. In addition, the results will allow the study of the dynamics and evolution scenarios of the combustion process in these fields, as well as the identification of hazards to the environment and human health

\section{COAL WASTE PILES}

The coal waste piles found over the old mine sites and adjacent areas represent significant environmental concerns due to their potential influence on soils and sediments, as well as on the surface waters and groundwaters of the surroundings. This is indeed a significant environmental problem in Europe, where for century's coal mines were intensively explored. For example, in the north of Portugal, close to Douro River, with its mouth in Porto, 28 of these piles were identified. One of these coal waste piles, located in S. Pedro da Cova, near Porto, started burning in 2005 after intense forest fires in the region, which caused their ignition, adding further environmental concerns. This waste pile is located very close to the oldest center of mining activities in S. Pedro da Cova and near to a population center and social infrastructures. This waste pile has an elongated form, occupying an area of approximately $28000 \mathrm{~m}^{2}$, with the burning process occurring in the south slope and moving along it (Figure 1).

The characterization of self-burning coal waste material and the combustion by-products (gases and coal fire gas minerals) is essential to address the environmental and human health effects. The results of geological studies indicate that an extensive variety of volatile organic compounds are released to the atmosphere (some of them at great concentrations) including, among others, greenhouse gases.

Due to its proximity to Porto, this coal waste pile was selected to test the optical fiber sensing system projected to assess the activity in the field. Owing this objective, preliminary measurements have been performed for general characterization of the waste pile, which included the monthly monitoring of its surface combustion temperature using infrared thermography. Figure 1 illustrates the temperature profile obtained in August and December of 2013 in the combustion area. The results acquired along these prior monitoring temperature campaigns will support the prototype design and installation for continuous measurement of temperature and gas emission.

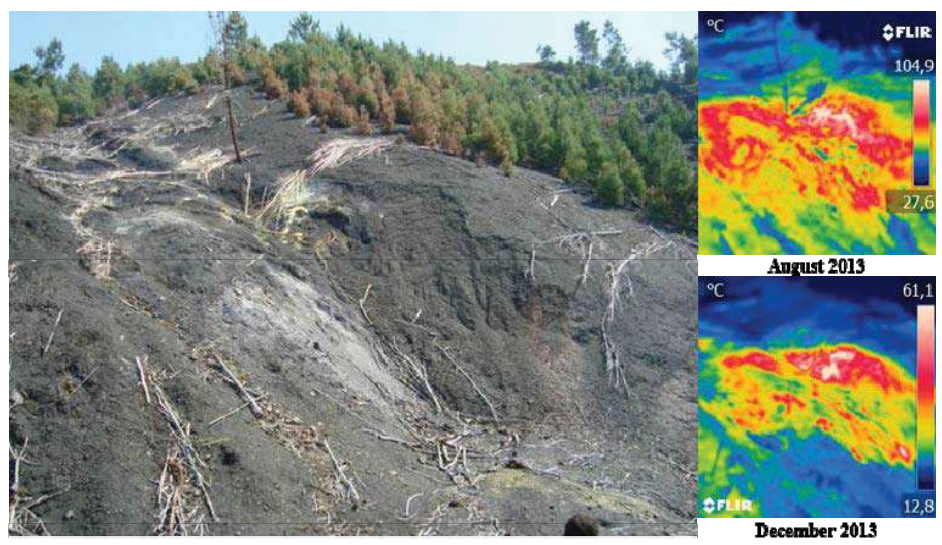

Figure 1. General view of the area under combustion and termographic images used for preliminary temperature characterization of the region.

\section{OPTICAL FIBER SENSING SYSTEM}

The implementation of the multi-point measurement system is quite a challenge due to the extreme conditions associated with the high temperatures experienced during combustion. However, it was realized the environmental importance of gathering information on the dynamics of these coal waste piles, which can be obtained from data associated with temperature measurement along the field and provides valuable insight on the underlying geological changes and spatial evolution of the underground combustion over time, as well as of the gas emission profile related with the combustion stage of the coal pile. When an assessment on the sensing technologies that could be applied under such harsh conditions 
was done, it became clear that fiber optics technology was the most adequate. Fiber optic sensors have proven themselves in harsh environments, presenting high sensitivity, wide bandwidth, high operation temperature, immunity to electromagnetic interference, lightweight, long life and multipoint and remote measurement capabilities ${ }^{7}$. Therefore, the project was built based on fiber optic technology for temperature and gas sensing, as described in next paragraphs.

The continuous monitoring of temperature over a wide surface poses several problems with conventional technology, which can be substantially avoided using distributed fiber-optic temperature sensing. In this case, Brillouin Optical Time-Domain Analysis (BOTDA) is proposed to monitor with a single-mode fiber layout extended over the whole area of the waste pile in combustion process. The BOTDA architecture used in this case is essentially similar to the conventional systems described in the literature ${ }^{3}$, except that the proposed system incorporates balanced detection ${ }^{4}$. Balanced detection provides substantial advantages in this case as it eliminates common-mode noise and provides an improved signal-to-noise ratio over the conventional single-detector systems. It also provides a better use of the dynamic range of the detector as it avoids saturation and allows higher input powers. High spatial resolution measurements are performed using the differential pulse-width pair technique ${ }^{5}$. This technique overcomes the conventional time-frequency trade-offs encountered in traditional BOTDA by subtracting the gain profiles obtained in the same position with slightly different pulse lengths. A resolution of 0.5 meters is thus obtained subtracting the results obtained with 40 and $45 \mathrm{~ns}$ pulses. As the two fibers are used in the cable, redundant measurements are obtained in each position. The temperature estimation is therefore achieved by averaging the results obtained from the two independent measurements realized in the same position. The general architecture of the fiber optic sensing system, including both the temperature and gas measurement systems (described above) is shown in Figure 2.

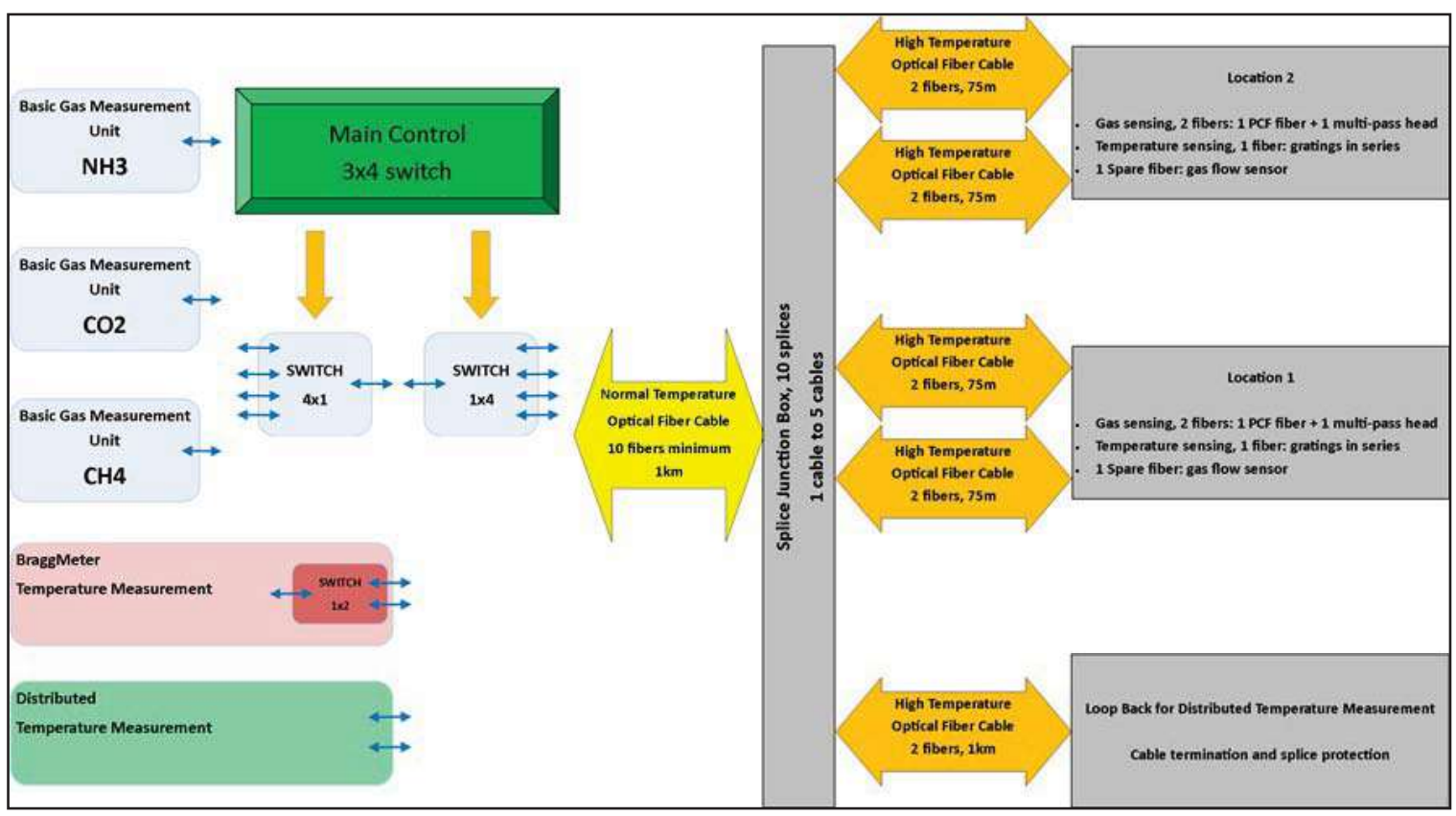

Figure 2. General architecture of the optical fiber system for gas and temperature measurement in coal waste piles.

For gas detection, the target is the measurement of ammonia, carbon dioxide and methane concentrations. An optoelectronic system has been developed based on Wavelength Modulation Spectroscopy (WMS) principle. WMS is a rather sensitive technique for detecting atomic/molecular species presenting the advantage that it has been used in the near-infrared region using telecommunication lasers. In this technique, the laser wavelength and intensity is modulated applying a sine wave signal through the injection current, permitting to shift the detection bandwidth to higher frequencies where laser intensity noise is reduced. The modulated laser light interacts with the absorption line of the target gas and, with proper processing, the amplitude of the second harmonic of the laser modulation frequency is proportional to the gas concentration ${ }^{6}$. Using WMS, two types of sensing heads will be developed, one based on free light propagation and another based on microstructured optical fibers with gases diffusing in their holes, permitting redundancy operation and technology validation. In order to have flexibility on the optical power levels, the sensing system will incorporate the functionalities of optical amplification and optical attenuation. In-field application, a special 
optical cable that stands high temperature will be used. For gas measurement, two different locals in the coal waste pile will be selected. The cable for temperature distributed measurement will essentially run on the surface of the field, but in some regions it will be buried to a certain extent to get information on the depth temperature profile.

Figure 3.a illustrates some of the results obtained in laboratory conditions of the sub-system for gas sensing, considering methane and carbon dioxide measurement. A multi-pass cell sensing head with $80 \mathrm{~cm}$ of optical path length was used and the DFBs lasers work at wavelengths of $1653.72 \mathrm{~nm}$ (for methane detection) and $1572 \mathrm{~nm}$ (for carbon dioxide detection). Sensitivities of $0.44 / \%$ and $0.05 / \%$ for methane and carbon dioxide measurement can be observed respectively. Figure 3.b shows an aerial view of the coal pile with indication of the monitoring region.

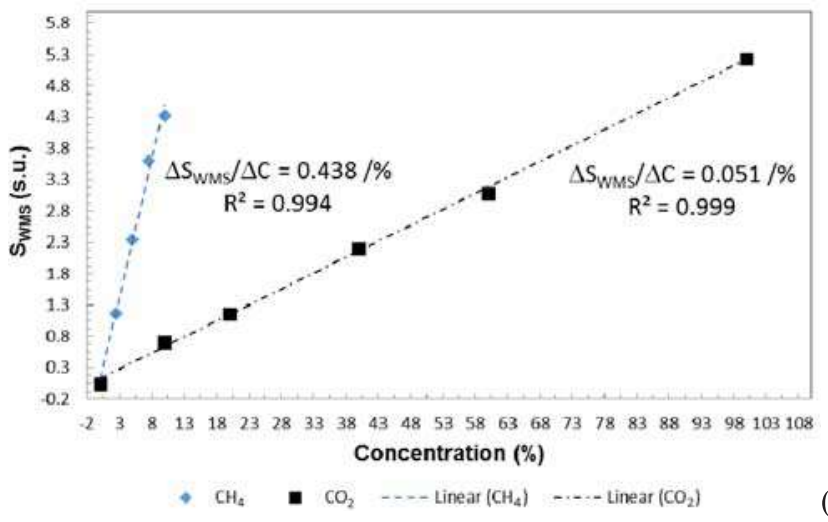

(a)

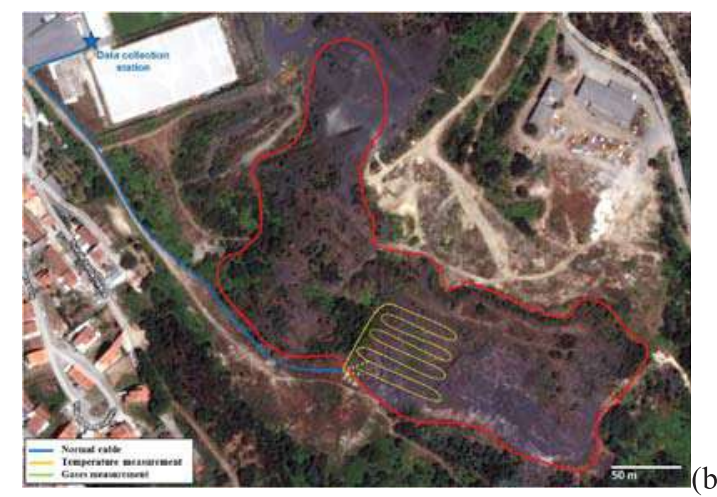

Figure 3. (a) Data obtained from the WMS interrogation approach versus methane and carbon dioxide concentration and (b) aerial view of S. Pedro da Cova coal waste pile (red contour), showing also the region of distributed temperature measurement (yellow line).

\section{CONCLUSIONS}

This work presents the problematic of self-burning coal waste piles and describes a project aiming the development of a fiber optic sensing system for real time monitoring of combustion temperatures and gas emissions, with its performance evaluation derived from a prototype installation in an active coal waste pile. The central goal is that this sensing system will contribute to the study of the combustion process dynamics and to set evolution scenarios of such fields, enabling the establishment of measures to minimize the environmental negative impacts originated from these wastes.

\section{ACKNOWLEDGMENTS}

This activity is supported by the project ECOAL - MGT - SOE3/P2/P714, Ecological Management of Coal Waste Piles in Combustion, SUDOE - Interreg IV B.

\section{REFERENCES}

[1] Ribeiro, J., Ferreira da Silva, E., Flores D., "Burning of coal waste piles from Douro Coalfield (Portugal): petrological, geochemical and mineralogical characterization", Int. J Coal Geol 81, 359-372 (2010).

[2] Suárez-Ruiz, I., Crelling, J.C., "Applied coal petrology. The role of petrology in coal utilization", Elsevier, 388 pp (2008).

[3] Niklès, M., Thévenaz, L., Robert, P. A., "Simple distributed fiber sensor based on Brillouin gain spectrum analysis," IEEE J. of Lightwave Technol. 15(10), 1842-1851 (1997).

[4] Domínguez-López, A., López-Gil, A., Martín-López, S. and Gonzalez-Herraez, M., "Signal-to-noise ratio improvement in BOTDA using balanced detection", IEEE Photonics Technol. Lett. Accepted (2013).

[5] Li W., Bao X., Li Y., and Chen L., "Differential pulse-width pair BOTDA for high spatial resolution sensing", Opt. Express 16, 21616-21625 (2008).

[6] Hodgkinson, J., Tatam, R. P., "Optical gas sensing: a review", Measurement Sci and Tech 24 (1), 012004, 59pp (2013).

[7] Pinto, A.M.R., Lopez-Amo, M., "Photonic Crystal Fibers for Sensing Applications", J Sensors 2012, 598178, $21 \mathrm{pp}(2012)$. 